\title{
Juxtaposition of Hohfeldian Rights, Principle-Based Ethics, Functionings, and the Health-Seeking Behavior of Sub-Saharan Africa
}

\author{
Ishmael D. Norman ${ }^{1,2,3 *}$, Blandina M. Awiah Norman ${ }^{2,4}$ \\ ${ }^{1}$ School of Public Health (Hohoe Campus), University of Health and Allied Sciences, Ho, Ghana \\ ${ }^{2}$ Institute for Security, Disaster and Emergency Studies Sandpiper Place, Langma, Ghana \\ ${ }^{3}$ African Academy for Environmental Health Sciences (AAEHS), University of Malawi, Chichiri Blantyre, Malawi \\ ${ }^{4}$ Consultant, Ghana Health Service Ministries, Accra, Ghana \\ Email: ${ }^{*}$ ishmael_norman@yahoo.com, blandinaawiah@gmail.com
}

How to cite this paper: Norman, I. D., \& Norman, B. M. A. (2016). Juxtaposition of Hohfeldian Rights, Principle-Based Ethics, Functionings, and the Health-Seeking Behavior of Sub-Saharan Africa. Advances in Applied Sociology, 6, 344-362.

http://dx.doi.org/10.4236/aasoci.2016.610026

Received: August 18, 2016

Accepted: October 21, 2016

Published: October 24, 2016

Copyright (c) 2016 by authors and Scientific Research Publishing Inc. This work is licensed under the Creative Commons Attribution International License (CC BY 4.0).

http://creativecommons.org/licenses/by/4.0/

\section{(c) (i) Open Access}

\begin{abstract}
Principle-based ethics appears to be recent addition to Sub-Saharan Africa's rights profile, although universal principles of morality have been part of the region from time immemorial. In this regard, periodic review of how principle-based ethics is being integrated into the health-seeking behavior of Sub-Saharan Africa is essential to the capabilities and functionings of the people. Whether the Hohfeldian incidents should be applied to Sub-Saharan Africa in measuring the degree of autonomy, capacity and informed consent, given the limited actual and medical education. Whether ethical concepts of "responsibility" and "paternalism" should be more promoted and if so, what happens to their "functionings" and "being"? The author examined the literature on ethics, searched databases for reports and published papers in the English language. Hand searching of selected printed journals and grey literature such as technical reports and conference proceedings were also accessed and briefed for further analyses. This shows that Hohfeldian rights are a natural part of African ethics. Principle-based ethics does not incorporate African ethics per se, although physicians', and decision experts' paternalism enhances the health-seeking behavior of Africa's people, it interferes with their "rights", "claims", "power" and "privilege", as well as their capabilities and functionings. Hohfeldian rights relate to Sub-Sahara Africa as universal man and amalgamate with African ethics and morality through the paternalism of doctors, community leaders and other "decision experts" in society in general. The application of the principle-based ethics in the healthcare delivery system and in other endeavors of Sub-Saharan Africa is achieved through the paternalism of superior powers. This compromises the functionings and being of the people.
\end{abstract}




\section{Keywords}

Hohfeldian Incidents, Principle-Based Ethics, Capability, Functionings, African Traditional Ethics, Sub-Saharan Africa

\section{Introduction}

In this paper, the author has applied the Hohfeldian Incidents of "right", "power", "privilege", "claim", and "immunity" to evaluate within the context of Sub-Saharan Africa, the operationalization of principle-based biomedical ethics of "autonomy", "capacity" and "informed consent" in the healthcare delivery system and in other endeavors. This is set against the ethical concepts of "paternalism", and "responsibility". By this, assuming the principle-based ethics is not suitable for the sub-region, would it be ethical for physicians, in terms of healthcare, and other decision experts, in terms of day-to-day life choices, to assume the paternal role? There are also series of inquiries of how the application of biomedical ethics can enhance the capabilities of Sub-Saharan Africa so that "all of Sub-Saharan Africa has enough goods (and services) to be fully human", in their health-seeking behaviors and in other industry (Goulet, Working Paper No. 231, 1996: p.4).

But first, the focus of this paper for the initial part is on the universal development of biomedical ethics vis-à-vis African ethics. The development of biomedical ethics for the humane, efficient and effective administration of the healthcare delivery system, the enhancement of public health services and for the general developmental activities would form the foreground of this paper.

\subsection{A Brief History of the Commencement of Universal Application of Biomedical Ethics}

Without condescension or condemnation, perhaps, it is safe to say that in Sub-Saharan Africa, there are many patients or people, to whom and for whom biomedical ethics as practiced today by researchers and clinicians, can be said to be nothing more than moral and ethical placebos.

This is because many a patients, many of the people of Sub-Sahara Africa, even healthcare providers and some medical doctors do not really understand what biomedical ethics is or how it is supposed to work (Edwin, 2009; Norman et al., 2014, 2015, 2016a). Before providing the rationale for this observation, it is important to review how biomedical ethics has been operationalized in both epidemiological research, and

in clinical and public health practice as a matter of universal concern (Norman et al., 2015; Edwin, 2009; Gostin, 2002; Coughlin, 1999; Emmanuel \& Emmanuel, 1992).

The mid 1960's marked the beginning of the universal observance of biomedical tools such as autonomy, capacity, informed consent and choice, to mention but a few. These principles have since been touted as part of best practices (Beauchamp \& Childress, 2001; Coughlin et al., 1999; Nuremberg Code, 1947; Helsinki Declaration, 1964; 
1967). The process towards the setting out of a universal ethical standard started by mistakes and intentional criminality.

In 1937, a case of mistake was made against a drug called Sulphanilamide. Sulphanilamide was used in the United States of American as antibiotic. By mistake the drug was mixed "with the solvent diethylene glycol, a known toxin" to make it easier to dissolve. The bad mixture of the two substances led to the death of more than 100 people, many of them children. "The catastrophic event prompted the passage of the 1938 Federal Food, Drug, and Cosmetic Act" (Martin, 2016). Then again, at the end of the $2^{\text {nd }}$ World War, and during the trial of some members of the Nazi Regime, it was discovered that the regime with some of its medical doctors had carried out atrocious medical experiments. Some of those experiments were conducted on Jews, Homosexuals and other ethnic and racial minorities, including women and children as well as other vulnerable persons such as those with intellectual or physical disabilities. The prosecution team at the Nuremberg Trial presented a six-point parameter to guide scientific research after the trial. The aim was to prevent those atrocities from being perpetrated ever again. The six-pointer became a ten-point code which WAs popularly known as the Nuremberg Code (Annas \& Grodin, 1992). In 1964 after deliberations of the World Medical Association in Helsinki, the ten-pointer morphed into the Helsinki Declaration, which was to provide the highest ethical standard for patient and people protections with respect to clinical and epidemiologic research (WMA, 1964). Despite this achievement on the international scale with the events leading to the Helsinki Declaration, there were differences in the ethical standards of the various member states or economic blocs that consisted of the World Medical Association at that time.

\subsection{Adverse Outcomes of Competing Ethical Models of Various Nations against Universality}

Such differences for black people in the United States were a very meaningful gap. It was also discovered that the Helsinki Declaration of 1964 was not a universal code after all. That, even if it were, it was severely limited by the competing ethical regimes and segregated national culturally relative ethical codes (Rachels, 2003). A case in point is, despite the Nuremberg Code and the Helsinki Declaration existence and impact, researchers at the Tuskegee Institute, Tuskegee, Alabama, carried out medical experiment on 399 black men with syphilis, and with the participation of the United States' Centre for Disease Control, Atlanta, Georgia in 1932. This experiment was found to have been unethically conducted over the period with respect to the treatment of the 399 cases (Heller, 1972). But in the control group were 209 participants, where the experiment was in compliance with the existing protocol. The details of this experiment of which Jean Heller of the Associated Press reported in 1972, "was never clandestine". At least 15 scientific, peer reviewed papers were published about the outcomes over time. During this time some 124 black medical students worked on the project. The 399 cases went untreated for 40 years during which period some succumbed to the ravages of the disease. During the Tuskegee experiment, penicillin, an effective drug against syphilis 
was discovered but the Tuskegee scientists chose not to give the participants the drug just to see how the subjects would behave as the disease progressed (Heller, 1972).

\subsection{The Sub-Saharan Africa's Role in WMA Conference, If Any?}

In all of the previous deliberations of the WMA, Sub-Saharan Africa was possibly absent. Their absence from the World Medical Association meetings, though not a minor oversight, was probably not even noticed by the world community. The organizers of the nascent universal ethical body's meeting for research and practice was perhaps pre-occupied with the incidents involving the Nazi atrocities, Sulphanilamide and others yet to come. Sub-Saharan Africa's ethical concerns were far away because during this time, the area was pre-occupied with the struggle for political autonomy not protection under autonomy as an aspect of biomedical ethics or public health. Granted many of the nations in Sub-Saharan Africa did not even exist as sovereign nations as we know them today. Ghana, the first independent nation in Sub-Saharan Africa achieved this objective only in 1957 with very weak national public institutions, and as it turned out; a megalomaniac bureaucracy and central government, with un-trained and unexposed personnel that simply could not have effectively participated in the World Medical Association's deliberations, perhaps (Norman, 2016b; Fanon, 1961).

It is, therefore, safe to say that the ethical views and concerns of the people of SubSaharan Africa were not expressed at the so-called World Medical Association deliberations that led to the 1964 Helsinki Declaration. Although currently nations like Ghana, with the European Union as lead partner are reported to be incorporating General Good Clinical Practice in their respective national legislations on clinical trials, much of what may be the result would not speak to the real needs of the uneducated, marginalized and economically vulnerable members of these societies. Whatever is decided would be normatively paternalistic by decision experts who are marginally familiar with the social settings of the marginalized (Ghana FDA-GCP Training Manual, 2015; Andersson, 2013; Cruft, 2010; 2004; Bentham, 1796).

In the meanwhile, in the 1960's, Europe discovered Thalidomide as a cure against pregnancy related insomnia. The drug was marketed in the United States of American and was well received by patients, but it was later discovered that it caused birth defects and malformations (Smithells, 1962, 1973). The outcome of the Thalidomide incident, coupled with other incidents arising out of prescription drug use and medical applications, there was the need to call for the harmonization of the competing ethical codes. As noticed, even in the western industrialized world, with very high educated population and medical expertise, understanding for biomedical ethics and related issues has not been an easy development. It should be expected that even in the Western Industrialized nations many people do not understand biomedical ethics, let alone those in economically challenged markets like Ghana. Additionally, there are issues of policing or the enforcement of the rights and privileges of ethics as a mainstreaming challenge.

\subsection{Who Is to Observe Patients' and People's Rights and Privileges?}

What is interesting about this proposal for the mainstreaming of biomedical ethics in 
Sub-Saharan Africa is that, in this region responsibility is placed on the caregiver to observe such rights and privileges without a concomitant obligation on the possessor of these rights to also observe them. An individual then can choose to be ignorant about the ethical code that governs or ought to govern his or her needs, even if he or she has the capacity to understand them. Incidentally, many a patients often do precisely that: remain ignorant about the medico-legal ethics that concern them. Many a researchers and graduate school students also choose to omit such knowledge in their professional lives and careers (Goodman, 2010; Braddock III, 1999; Coughlin et al., 1999).

It seems it is assumed in the society that the possessor of such ethical rights has no obligation to observe the rights he already owns contemporaneously, until there is some form of omission or commission of a tortious act against the holder of the rights (Andersson, 2013; Braddock et al., 1999; Braddock et al., 1997). For example, if a patient elects to be indifferent about receiving healthcare from facility A or B, but complies with a suggestion from an administrator at facility $A$ to go to facility $B$ to be cared for; even though the patient is already at facility A. The patient dies on the way to facility B. Should the administrator be held responsible? Before this can be answered, factual information is needed to reach a convincing conclusion under this situation. Was the referral the proximate cause of the patient's death or there was a pre-existing circumstance or an intervening event that caused his death? To decide on a matter such as this, the entire situation, including the circumstances leading to the suggestion that the patient goes to another facility for care as well as the patient's medical history would have to be subjected to meta-ethical evaluation. Without first exhausting the procedural issues with regards to fact finding, it would be difficult to arrive at a just conclusion (Hedahl, 2013; Cruft, 2004; Holmes \& Sunstein, 1999). In the same vein, in order for the people of Sub-Saharan Africa to understand and appreciate, in fact, enjoy their autonomy and the related privileges they naturally have, they need to first; understand that they are in possession of such rights and privileges set against other natural restrictions (Hohfeld, 1919; Johnson, 2014; Deneulin \& McGregor, 2009: pp. 1-3). The ethical rights of the people of Sub-Saharan Africa ought to be enabled by legislation, since these are not only human rights matters but also substantive and procedural matters as well. We would now turn to how the Hohfeldian incidents can relate to normative ethical and moral standards of Sub-Saharan Africa.

\subsection{Hohfeld on the Competition between Rights, Privileges, Power and Claims vis-à-vis African Ethics}

In Hohfeld's articulation of the rights and privileges of the individual, he did not predicate his ethical matrix on rationality alone but also on nature. Human beings are social entities and as social entities, the share a common destiny, rights and privileges, and therefore deserve common normative moral and ethical basis for the evaluation of their conduct. Hohfeld described the attributes of these rights and the circumstances under which they could be exercised, compromised, encroached upon, or even abused by higher, "decision experts", as humans try to express them-selves in the pursuit of wellbeing and material progress (Hohfeld, 1919; Sen, 1979, 1995). For the expression of 
the will of man in the pursuit of his dreams and aspirations, in the pursuit of the things that are meaningful to him, man needs to do more than to observe the measurement of his ethical rights against those of his neighbors. He needs to have the ability to conduct an assessment of his conduct and to design the changes and initiate the actions that would bring him to his goals. For this part of the analyses, we turn to the Capability Approach for guidance.

Amartya Sen (1979) couched the capacity of the individual to enjoy his rights and privileges on rationality in his descriptions of development ethics and economics. Sen provided that a person's sense of self begins from his or her "capabilities". In throwing light on Sen's Capabilities Approach, Deneulin and McGregor (2009: p.2) offered that the capabilities approach has three main concepts: functionings, capabilities and agency. Sen defined functionings as "the various things a person may value doing or being", which allows him to do meaningful things (Sen, 1999: p. 75). Capabilities means the "freedom to do valuable things" or the "various combinations of functionings (being and doing) that one can achieve". That is to say, capabilities are, thus, a set of vectors of functionings, reflecting the person's freedom to choose the kind of life one wants to lead (Sen, 1999: p. 87; Deneulin \& McGregor, 2009: p. 2). Capacity or rationality ought to be part and parcel of one's expression of capabilities without which, there may not be the functionings that allow one to do and be. That is to say; his or her ability to do meaningful things for himself and herself in order to enjoy happiness or pleasure, depends on his or her capabilities irrespective of the economic or political or social environment within which he or she may find himself or herself (Sen, 1999; Deneulin \& McGregor, 2009).

If man is a social being, then he cannot simply decide to do whatever he wants to do without societal limitations and restrictions. For example as part of "T"s functionings, "T" likes to snort cocaine during office hours and wants to sit at his office desk to do it in view of his co-workers. Shouldn't society, his supervisor and co-workers allow him to do so since this may probably enable him to give his best to the company, shareholders and society at last? Perhaps, under the rationality test, this example would fail, but it shows how absurd the "agency" rationale could get without self-restraint.

Does it also mean that if a person is not able to do meaningful things for himself or herself, even though the person shows a great deal of joy and happiness and has a sunny disposition in the face of dire situations that such a person is operating under "false consciousness?" Deneulin and McGregor (2009: p. 8) citing Lockwood (1981) and Scott (1975) argued that:

Such an approach enables researchers and policy makers to discount or devalue the meanings and understandings that form the basis for poor people's decisions and actions and in doing so, opens the way for forms of paternalism where there is an assertion of "superior" values and meanings which arise from higher authority or from a position of more enlightened understanding.

Deneulin and McGregor agree with Lockwood and Scott's argument in the quotation that, poor people can and do really think just as well as enlightened people do. That, the 
sense of wellbeing of poor people may not be determined by a higher authority and but by themselves. The thought that emerges at the end of this discourse is that the capabilities approach cannot work for everyone, especially people who are poor, who have inferior values and are unenlightened. The capabilities approach seems to be for an economic and intellectual class of people who already know what they want and how to pursue it.

\subsection{Aggregation of Superior Values, Decision Experts, and Hohfeldian Rights and Its Possessor}

In relation to superior values, Hohfeld did not look outward to find the "decision expert" as provided by Sen (1995: p. 5) in his writing of the capabilities approach and cited in Deneulin and McGregor (2009: p. 12). Under the Hohfeldian model, the possessor of the rights may express them or reject them as he pleases so long as he does not interfere with the rights of others. This argumentation invokes Mill's dialectics that "the sole aim of restricting personal freedom or the exercise of personal freedom is to prevent harm to others..." and that "the only part of the conduct of anyone for which he is amenable to society is that which concerns others" (Mill, 1859; Sen, 1982; Human Development Report, 1990, 2015). The way human beings pull together to form a society also requires of them to respect the competing rights of others (Hedahl, 2013; Kamm, 1992; Rachels, 2003).

For there to be harmony in thought, action, and industry, there had to be a way to juggle the rights of the people in society and select the best option for each situation, taking into consideration the concerns of the collective. To aid society on how to take into deliberation the needs of everyone, he considered the nature of the competing rights. He discovered that "rights" such as the right of autonomy or informed consent has complex internal components that are structured like most molecules with arranged chemical elements into four basic units (Louden, 1983; Kamm, 1992; Stanford CSLI, 2016). These elements, Hohfeld noted, were grouped as "privilege", "claim", "power" and "immunity", which are otherwise called, the "Hohfeldian Incidents". Hohfeld proffered that each of these elements had distinct logical form that fit together to create a "molecular rights". That is to say, each of the elements is part and parcel of the particular right a patient may express. In the case of Privilege, scholars at Stanford illustrated Hohfeld's thesis that: if a patient has a right of autonomy, it also means that patient's right of autonomy is a privilege. Therefore the patient only has a privilege of autonomy if and only if the patient has no duty not to express autonomy. That is to say the patient would not violate any duty not to exercise his autonomy (Stanford CSLI, 2016). If the right to do meaningful things under Sen's Capabilities Approach is only a privilege to do those things of value to one, then the individual does not really own himself, since he does not have the freedom to act. Curiously, within African indigenous ethics and morality, Hohfeld's balancing of competing rights resonates more with the reality of life than even the principle-based ethical rights. In African ethics and morality, the individual exists for the community, and autonomy, capacity and informed consent are shared values (Norman, 2016 a, b; Ekeopara \& Ogbonnaya, 2014; Udokang, 
2014; Onunwa, 2008; Ross, 2010; Murove, 2009; Osei-Hwedie, 1997).

\section{Method}

\subsection{The Internet and Hand Search Strategy}

The author searched databases such as PubMed, Elsevier, Hunari, WHO Bulletin, Medline and others for reports, editorials and published papers in the English Language. Medical Journals in Sub-Saharan Africa and elsewhere were also searched for publications on "paternalism in medical practice in Africa". Other themes for internet searches were: 'Show nexus between Hohfeldian Incidents of 'right'; 'power'; 'privilege'; 'claim'; and 'immunity' and Africa", "How to evaluate principle-based biomedical ethics in SSA". "How do the locals appraise 'autonomy', 'capacity' and 'informed consent' in Ghana's healthcare delivery system and in other endeavors?" "What value is placed on 'paternalism', and 'responsibility' in Ghana?'

These searches yielded over 500,000 entries and "paternalism in medical practice in Ghana" alone yielded 2.1 million but more than $99 \%$ were not relevant. Hand searching of selected printed journals as well as searching through technical reports, conference proceedings and workshops at the library of the College of Surgeons and Physicians, Ridge, Accra, Ghana, was also conducted. The material found were assessed for relevancy and relatedness, then briefed for analyses.

\subsection{Inclusion and Exclusion Criteria for the Assessment of Effects}

The author adopted strict inclusion criteria for the papers reviewed for this article. About (66) sixty-six publications, which met the inclusion criteria out of over 200,000 articles, opinions, blogs, grey literature and policy documents were reviewed, briefed and analyzed for this paper. Each paper was assigned an overall score. A score of: $1=$ Entirely Relevant (ER); 1/2 = Somewhat Relevant (SR); and $0=$ Not Relevant at All, $(\mathrm{NRaA})$ against the themes used in this paper as adopted from government's program goals. The selected papers were rated and the papers that received scores above 2.5 out of 4 in this evaluation were further analyzed. The findings were summarized into their respective units, and interpreted based upon the authors' skills and knowledge in ethics, health policy, public health and law. The authors excluded papers and reports that did not provide additional material on the previous selection. In addition, Epidemiological investigation into any of the themes contained in this paper was not conducted but relied on existing literature.

\subsection{The Approach Adopted for the Paper}

The authors examined the literature on ethics, searched databases for reports, editorials and published papers in the English Language as shown above. The literature review first considered the historical antecedents and the development of pertinent ethical principles, starting with the 1937 Sulphanilamide case to the discovery of the Tuskegee Institute ethical abuse of 399 syphilis patients and the ethical developments that emerged following the Nuremberg Trial of some officers and operatives of the Nazi re- 
gime. The literature revealed how little role was, in fact, played by the nations in SubSahara Africa. It also showed how their lack of actual involvement and ownership in the development of universal principle-based ethics makes the mainstreaming of these principles difficult in Sub-Saharan Africa. This is coupled with the lack of actual and medical education on the part of the population.

The analyses were linked to the expected effects of these principles in the lives of patients and people using the Hohfeldian hierarchy of rights as the starting point. The effect of these principles were then juxtaposed with the functionings, doing and being of people, since the whole purpose of principle-based ethics seek to enhance the capabilities, wellbeing and freedoms of not only patients, but people in general to do the things that make them fully human. In this respect, some aspects of Amartya Sen's capabilities approach was employed as the basis for evaluating autonomy, capacity and informed consent in health seeking behavior and in industry, since it provides a well-thought out intellectual and practical basis for such assessment.

\section{Result and Discussion}

\subsection{The Right of Autonomy as "Privilege”, "Right", "Duty” and Capability}

Hohfeld's analysis shows that, because the right of autonomy is both a privilege and a right and that the owner of this privilege-right dichotomy can choose to exercise or not to exercise it, then it must be shown also that the possessor of these rights understands them to be exclusive to him.

If the patient makes a rational rejection of his right of autonomy or chooses to ignore it in his dealings with the caregiver or third parties, then its enforcement on the caregiver may be coercive and unequitable. That is to say, a medical doctor has a higher duty of care to the patient than the patient himself to himself, which appears to tilt the argument in favor of paternalism and responsibility more than any other ethical principle. The underlying assumption here, as alluded to earlier, is that the possessor of such rights has no obligation to observe the rights he already owns until there is some form of omission or commission of a tortious act (Brett, 1997; Darwall, 2006). The author considers that Hohfeldian analysis also shows that "duty" to one's self becomes a substitute for capability. The expression of autonomy is the duty of the individual, assuming that that individual has the capability to express autonomy in the first instance. Sen presented that despite the autonomy holder being the "primary obligor" of duty, there is a binary responsibility to third parties and in this case, the healthcare giver (Sen, 2001; Stanford CSLI, 2016). Hohfeld's "claim" right also presumes that the "primary-obligee" or the care-giver is also a duty bearer and for this reason, has to recognize that the patient has a right to "claim" his autonomy or not. That the "primary- obligee" should know and should have known that even if the claim is not exercised, it is still the responsibility of the "primary-obligee" to protect the autonomy of the patient with or without his tacit consent for protection (Stanford CSLI, 2016).

That is to say, the patient's "claim-right" exists independent of himself or herself and independent of action or inaction, or conscious or unconscious. This is akin to statuto- 
ry obligation or a statutory right of the patient or people. For example, a statutory right of one called, "P" can still be breached by another, called "Y" if "P" ignores the statutory nature of "Y"s rights. For example if an adult male has sex with a seventeen year old female in a nation where the age of majority is set at 18 , such activity is considered rape according to law even if there was consent on the part of the seventeen year old teenager. The law has taken the position that the seventeen year old female does not have the capacity to consent and therefore would hold the adult male with a rape charge, because the adult man is deemed the fiduciary of the teenager and also a superior "decision expert". In the health care delivery system, biomedical ethics deems the care-giver or "primary-obligee" as the fiduciary of the patient's "claim-right" of autonomy.

In relation to "power-right", Hart, (1994) “...posited that there are two basic 'rules' to help to define the Hohfeldian power incident, which consist of 'Primary' and 'Secondary' rules". By primary rule, Hart meant the incident that enables agents to alter primary rules: $A$ has a power if and only if $A$ has the ability to alter her own or another's Hohfeldian incidents'. Still on the primary rules, the "power" element within the Hohfeldian Incidents is the ability of the power-right holder to alter the authority of an agent or another to perform an act or refrain from performing an act which interferes with the agent or other person's Hohfeldian privilege-right. "Power-right can be macerated or encroached upon by ordering it, promising, waiving, sentencing, consenting, selling and abandoning it" (Hart, 1994; Stanford CSLI, 2016).

\subsection{Right as Power, Privilege, Claim and Immunity vis-à-vis Capabilities}

The last Hohfeldian Incident also offers "Immunity" to the possessor. For example: $B$ has an immunity if and only if $A$ lacks the ability to alter $B$ 's Hohfeldian incidents' (Hart, 1994; Stanford CSLI 2016). When another person cannot alter the Hohfeldian right or incident of another, it is presumed that the person whose right cannot be altered has immunity.

In our modern globalized world, education within and outside of the classroom enhances first the perception of rights and the actual exercise of one's capabilities in order to "do meaningful things" for one's self. For example, a person who cannot read and write may not fully exploit either his Hohfeldian rights or his "capabilities" in a meaningful way (Seers, 1969: p. 10). In the case of Ghana, those aged 15+ and who can read and write are only about $58 \%$ of the population of about 25 million, according to the 2010 Census. Literacy rate among males is $66.4 \%$ whiles among the females it is only about $49.8 \%$ also from the same source. In the 1990 's the ratio of medical doctors to patients was 1:22,590. This may have improved marginally since the 1990's. Today, maternal death ratio is $350 / 100,000$ births whiles the national target was $180 / 100,000$ births. About $57 \%$ of births are skill deliveries while over $40 \%$ are unskilled deliveries. The Ratio of Midwifes to population is 1:5300 in Ghana, with a shortfall of 5000 Midwifes (Norman, 2015; Ghana Statistical Service, 2010). The question is how can a population with such characteristics be able to translate principle-based ethics into the general conduct of the people? 
In Sub-Saharan Africa, the lack of actual and medical education render patients' autonomy, capacity and informed consent as moral placebos, when viewed in the context of the Hohfeldian Incidents of "privilege"; "claim"; "power" and "immunity". Under such a situation, "responsibility" and "paternalism" appear to be the overriding ethical values worthy of following in Sub-Sahara Africa's zone of the medical world (Norman et al., 2015; Norman, 2016b). How does the ethical value of responsibility translate into action or deeds to protect the actual substantive rights of patients and the rights of the care-giver both as a fiduciary and as a provider of health care services? "When it comes to patient rights in Sub Saharan Africa, a different set of ethical standards needed to be developed. Pure reliance on the western biomedical model of autonomy, informed consent, capacity, and choice, to mention but a few, would not actually enhance patients" rights but would diminish these rights substantially without the active participation of the care-giver as "decision expert" (Norman et al., 2015).

The definition of capacity is again one of the major challenges with ethics in Sub-Sahara Africa as articulated by Beauchamp and Childress, (2002). It is even more difficult to assess the capabilities of a group of people who lack exposure, information, visual experience or familiarity with a particular action except for the most basic of amenities, in relation to their functionings and utility (Goulet, 1971; Myrdal, 1969).

\subsection{Does Capabilities Approach Mean the Same Thing Everywhere?}

Sen (1985) defined capabilities in a linear progression: from commodity to function or functioning to utility or happiness. He also argued that wealth is not the only thing human beings want and that material things cannot make one happy. They also want other things and therefore cannot use wealth as the denominator to determine the quality of life of all people, since people have different goals and aspirations even within the same perhaps, homogenous society (Sen, 1982). For instance, in the United States, citizens have a hypothetical "right" to vote. To Sen, this concept is fairly empty. In order for citizens to have a capacity to vote, they first must have "functionings". These "functionings" can range from the very broad, such as the availability of education, to the very specific, such as transportation to the polls. Only when such barriers are removed can the citizen truly be said to act out of personal choice. It is up to the individual society to make the list of minimum capabilities guaranteed by that society (Deneulin \& McGregor, 2009).

In Ghana today, there are marked differences between health and economic inequalities and inequities among the various classes of the population. Under the most recent constitution of Ghana, the 1992 Constitution, there is the general belief that all men and women, all rich men and poor men, all rich women and poor women, in fact all urban dwellers and village or town dwellers were created equal. They have equal protection before the law. But this is the belief. The reality of equality and of freedom is more nuanced, more a determinant of one's antecedents and more a function of one's education, where one went to high school and then secondary school and then which university one attended. Equality is measured by flexible moral standards and not the 
normative standards of law, reason and ethics (Norman, 2014). Freedom of association and functionings, doing and being are not as readily available to the people of Ghana as those in other climes. Tocqueville began his review of the freedom of association of the people of America by identifying three basic characteristics that exemplifies how Americans experience this phenomenon in their daily lives. He wrote that the people of America associate with each other for "the purposes of public security, commerce and industry, pleasure, morality and religion", despite their unflinching belief and knowledge "...he must depend on himself against the ills and difficulties of life" (Tocqueville, in Craiutu, 1999). In Ghana, believe in one's self is an abstract concept because selfedification or improvement, having a good work ethics does not often equal success. The people of Ghana are hopeful that tomorrow would be better than today. They do not however, assume that the ecosystem in which they find themselves would provide the ways and means for self-actualization without the aid of paternal force or figure. The people have hope in God. Hope in a deity. They have hope in the thought that someone somehow would show consideration towards them and treat their request, answer their prayer or need, favorably whether they work hard or not (Seers, 1969). The people believe in fate, predetermination of one's destiny, one's success, and one's capabilities in order to achieve the things or goals that are meaningful to them. This belief system underlines individual as well as national policies and programs. This belief system also, incidentally, though not yet empirically established, provides the perpetrators of corruption and rent-seeking behaviors in Ghana and in Sub-Saharan Africa as a whole the immoral and unethical justification for their participation in corrupt practices (Norman \& Aviisah, 2015).

In the same vein it is difficult to argue that the significant majority of the people of Sub-Saharan African, who cannot read and write and who live on less than one dollar a day have "functionings" and by extension understand issues of autonomy, informed consent and choice. They appear to be intellectually, socially and functionally handicapped so much so that their capacity to make informed consent is rendered reductive. The capabilities approach therefore cannot mean the same thing everywhere, considering the differential economic systems within which human beings find themselves.

\subsection{Informed Consent, Capacity and Capabilities}

The Council for International Organizations of Medical Sciences defines informed consent, at least, in research as "a decision to participate in research, taken by a competent individual who has received the necessary information and who has adequately understood the information. Who, after considering the information, has arrived at a decision without having been subjected to coercion, undue influence or inducement or intimidation" (Ghana FDA Training Manual, 2015; CIOMS, 1949). Many an epidemiologic data have been collected from unsuspecting participants who were made to believe that they have in fact given informed consent. In the first instance, in fact, they had not been given essential or material information about the study and therefore could not or did not understand the privileges and rights they had allowed to be en- 
croached upon by researchers with questionable ethics and veracities (Edwin, 2008, 2009). It is, perhaps, a monumental display of scientific trickery for a researcher to conclude that an un-educated mother who cannot read or write, and who allows her 5-year old child to participate in a scientific study after having being induced with a bar of soap, token transportation which actually goes beyond the cost of transportation from her abode to the place of the researcher, had understood the information about a given study and had given informed consent (Dworkin, 1988; Buchanan, 2008). The very reason why scientists may conduct research about a matter is because they themselves cannot answer the questions surrounding the matter and therefore carry out the research to break down the matter into its hidden parts, and to reveal the answers. How can such a researcher actually provide all the information necessary to another, educated or not, in order for the person to give informed consent? If one does not know what one is entitled to because one does not know one's rights and privileges, there can only be a general nauseating feeling of one that, one may be missing out on important rights and opportunities. It would be almost impossible for one to articulate with clarity the essential elements of what one may be missing, due to the lack of knowledge, education, information, and perhaps, experience. The lack of education, the lack of ability to read and, or, write; accompanied by the lack of comprehension of scientific information no matter how elementary a written piece of research literature may be, the lack of exposure coupled with the lack of sophistication, access to information as well as the lack access to material information, the lack of understanding of risk and its consequences, these may be as incapacitating as intellectual impairment and disability (Norman et al., 2014, 2015; Gillion, 1985). What role does the culture play in adjusting the expectations of people with differential vulnerabilities and capabilities?

\subsection{Cultural Ethical Relativism against Shared Capacity, Autonomy in Africa}

The author reverts to Rachels seminal discussion of Cultural Ethical Relativism to see if this concept would provide the response to how culture adjusts or moderates differential expectations. Rachels' central argument against cultural ethical relativism was based on the rationale that what is right or true depends on the culture's perspective (Rachels, 2003). He argued that the cultural differences argument was not valid, because the conclusion does not follow from the empirical premise that different cultures have different moral codes. By moral code, it is presumed that ethical code is also implied. If such were so, then, Rachels maintained, there can be no objective moral truths. To every general rule, there is an exception, despite the sheer strength of Rachels' intellectual clarification on the matter. In Sub-Saharan Africa, the individual may not be the possessor of capacity as an ethical value as it is in the Western Industrialized nations, but rather the family or community (Sivalingam, 2011; Norman, 2015). Rachels maintained that in minor cultural matters different cultural and ethical codes are acceptable. The issue of shared autonomy is a defining issue of great significance to the sanctity of a human being because it underlines his capabilities. Again another important matter is the issue of capacity. In Africa, capacity cannot always be said to rest with the individual, a fact 
of culture dictated by cultural relativism. For example, African ethics places premium on the inter-relatedness of people, communal decision making, respect, responsibility, hospitality and service to humanity (Ekeopara \& Ogbonnaya, 2014; Udokang, 2014; Onunwa, 2008; Ross, 2010; Murove, 2009; Osei-Hwedie, 1997). In such a cultural situation, the individual's contributions, while being praised may be considered important to the extent that it advances the community or communal interests over that of the individual. Although urbanization and its effects on behavior may have diluted the communal imperative on the actions of the individual to a large extent in today's Sub-Saharan Africa, there is still strong attachment to conventional edict that the individual puts the community before his or her own private interest (Ross, 2010).

Since capacity may be shared by the individual and his wife, son and father or a person and his family, its definition should; by cultural necessity not cultural relativism; be cognizant of this reality. The capabilities approach does not require a perfect world for people to function do the things they need to do in order to do the things they want to do, and conducting the affairs that allow them to live their best lives. In a democratic dispensation, although not a necessity, still it seems the capabilities approach requires that for the people to express their autonomy, choice, and make the decisions that may lead them to the kind of lives they want to achieve; they need to be part of the broader politico-social machinery. The capabilities approach cannot be said to operate in a utopia. It is a social concept erected on the collective consciousness of society that operates efficiently and effectively when society's members are free. Here, autonomy equals freedom and freedom becomes the moral equivalent of choice.

The population needs to be able to say such and such government policy would truncate their abilities to pursue their dreams and aspirations. They need to be listened too, and their needs addressed without coercion, intimidation, force or fear. Therefore, although political will or collaboration is not a requirement or even a necessary ingredient to enhancing the functionings, doings, and being of the population, a good ecosystem and good governance are the basic architecture, the sine quo non for the full exploitation of people's capabilities (Goulet, 1971; Seers, 1969).

\subsection{The Autonomy as a Mundane, Operational Rights Concept}

What appears to be missing even in the scientific literature and in practice is that autonomy by itself is not an unrestricted social ideal. As a human rights concept, it is subjected to sovereign encroachment and modification for the public good as well as for the good of the possessor of the privilege of autonomy (Hohfeld, 1919; Mill, 1859). Autonomy is like a well-constructed housing complex for the high-end home owner. It is admired from afar and near and constitutionally protected, at least with respect to the actual and residual interests in each unit. But the seemingly hard and constitutionally protected reality of the right to exclusive possession of such real property can easily melt away, when the government expresses its imminent domain powers over that parcel of land or property. When the government demands for it, with due compensation, to build a motorway through the neighborhood which once was the enclave for the rich 
and famous, the previous allure, with the well-manicured lawns and gardens, pulls away into oblivion. For autonomy or freedom to be experienced by the individual when receiving healthcare delivery or bureaucratic service, the overall national, regional, local culture about the rights of the individual should be embedded in the mundane social exchanges of the population. If the underlying culture does not on a day-to-day basis support mainstreaming of autonomy at home by spouses and parents, at work by supervisors and bosses, and between superiors and subordinates, it may not be easily expressed at the interface of healthcare or bureaucratic service delivery (GHS Patient Charter, Ghana Public Health Act, 2012 (Act 851). Freedom of information, a critical ingredient for functionings, doing and being, is still a virgin concept in many of the nations in Sub-Saharan Africa in science and scientific studies, in politics and in just about the daily endeavors of society. When the information relates to clinical trials or the conduct of experimental procedures in clinical settings particularly in remote health outposts, or in poorly supervised hospitals even in urban centers, there exists a world of secrecy and perhaps, misinformation (Edwin, 2009). Adverse information on drug trials the disclosure of which would lead to huge losses by a drug company may not in the interest of humanity be made available to the public and even to participants in the trial. Such shortcoming is not limited to the activities of some big pharmaceutical companies or practitioners of Traditional Medicines, but found among researchers in Epidemiologic studies (Norman, 2016b). There is really limited disclosure of material information which may not be enough to form the basis for informed consent (Ama Edwin, 2009).

Wherever patients and clients have limited access to information and material information about their health status, the healthcare delivery system relies heavily on the paternalism of the care-giver and service provider. Benevolent paternalistic care is not in conflict with beneficence and non-malfeasance. In fact, the end game of beneficence as a biomedical principle of ethics is synonymous with benevolent paternalism. Benevolent paternalism is where the care-giver does what is within his or her power to ensure that the best service or medical care is given to the patient at the right time and place. Such would have to be within the established protocol of his community, and to cure, protect and prolong the life of the patient. In such a situation, beneficence or benevolent paternalism metamorphoses into responsibility of the strictest kind for the care of the patient. The Hohfeldian Incidence does not advocate a strict observance of the ethical rights and privileges of the people. Like Sen's Capability Approach, it does not operate on in a perfect world. It only provides a matrix for weighing and measuring the competing rights and privileges of others or society that may be implicated in the expression of private rights.

\section{Conclusion}

The Hohfeldian Incidents, underlying biomedical principles of autonomy, capacity, and informed consent, occur in the medical and public health practice in Sub-Saharan Africa. Its operationalization in the lives of the people is of limited validity due to the 
lack of general basic and actual medical education when it comes to their health-seeking behaviors, let alone their social lives. No right thinking, ethicist, researcher, healthcare provider or the layman would deny the right of the population to express their autonomy, capacity and informed consent. However, the understanding of these concepts is at a superficial level. This fact renders the beneficiaries' limited experiential benefits in their health seeking behaviors during interface with healthcare and health services providers, the government bureaucracies and other national and municipal service providers.

\section{References}

Andersson, A.-K. (2013). Choices, Interests, and Potentiality: What Distinguishes Bearers of Rights? Journal of Value Inquiry, 47, 175-190. http://dx.doi.org/10.1007/s10790-013-9378-9

Annas, G. J., \& Grodin, M. A. (1992). The Nazi Doctors and the Nuremberg Code. New York, NY: Oxford University Press Inc.

Beauchamp, T. L., \& Childress, J. F. (2001). Principles of Biomedical Ethics (5th ed.). Oxford: Oxford University Press.

Bentham, J. (1796). Anarchical Fallacies. In Waldron 1987a, pp. 46-76.

Braddock III, C. H., Edwards, K. A., Hasenberg, N. M., Laidley, T. L., \& Levinson, W. (1999). Informed Decision Making in Outpatient Practice: Time to Get Back to Basics. Journal of the American Medical Association, 282, 2313-2320. http://dx.doi.org/10.1001/jama.282.24.2313

Braddock, C. H., Fihn, S. D., Levinson, W., Jonsen, A. R., \& Pearlman, R, A. (1997). How Doctors and Patients Discuss Routine Clinical Decisions: Informed Decision-Making in the Outpatient Setting. Journal of General Internal Medicine, 12, 339-345.

Brett, A. (1997). Liberty, Right, and Nature. Cambridge: Cambridge University Press.

Buchanan, D. R. (2008). Autonomy, Paternalism, and Justice: Ethical Priorities in Public Health, American Journal of Public Health, 98, 15-21. http://dx.doi.org/10.2105/AJPH.2007.110361

Coughlin, S. S., Katz, W. H., \& Mattison, D. R. (1999) Ethics Instruction at Schools of Public Health in the United States. Association of Schools of Public Health Education Committee. American Journal of Public Health, 89, 768-770. http://dx.doi.org/10.2105/AJPH.89.5.768

Craiutu, A. (1999). Tocqueville and the Political Thought of the French Doctrinaires, History of Political Thought (Vol. XX., No. 3). Princeton, NJ: Princeton, University.

Cruft, R. (2004). Why Is It Disrespectful to Violate Rights? Proceedings of the Aristotelian Society, 113, 201-224. http://dx.doi.org/10.1111/j.1467-9264.2013.00352.x

Cruft, R. (2010). On the Non-Instrumental Value of Basic Rights. Journal of Moral Philosophy, 7, 441-461. http://dx.doi.org/10.1163/174552410X535071

Darwall, S. (2006). The Second-Person Standpoint. Cambridge: Harvard University Press.

Deneulin, S., \& McGregor, A. J. (2009). The Capability Approach and the Politics of a Social Comception of Wellbeing. Wellbeing in Developing Countries, WeD Working Paper 09/43. Bath: Centre for Development Studies, University of Bath.

Dworkin, G. (1988) The Theory and Practice of Autonomy. Cambridge: Cambridge University Press. http://dx.doi.org/10.1017/CBO9780511625206

Edwin, A. K. (2008). Don't Lie but Don't Tell the Whole Truth: The Therapeutic Privilege-Is It Ever Justified? Ghana Medical Journal, 42, 156-161.

Edwin, A. K. (2009). Non-Disclosure of Medical Errors an Egregious Violation of Ethical Prin- 
ciples. GMJ, 43, 34-39.

Ekeopara, C. A., \& Ogbonnaya, L. U. (2014). Traditional Ethics and the Maintenance of Social Order in the Nigeria Society. European Scientific Journal, 10, 34-46.

Emmanuel, E. J., \& Emmanuel, L. I. (1992). Four Models of the Physician-Patient Relationship. JAMA, 267, 2221-2226. http://dx.doi.org/10.1001/jama.1992.03480160079038

Fanon, F. (1961). The Pitfalls of National Consciousness, Chapter 3. The Wretched of the Earth, https://www.marxists.org/subject/africa/fanon/pitfalls-national.htm

Ghana Food and Drug Agency-GCP Training Manual (2015). Power Point Presentation, Training of Research Team on Proposed Ebola Virus Disease Vaccine Trial. Accra: School of Public Health, University of Health and Allied Sciences, Hohoe Campus, Food and Drug Agency.

Ghana Health Services (2012). Patient Charter, Ghana Public Health Act (Act 851). Accra: Government Printers.

Ghana Statistical Service (2010). The Annual Statistical Survey. Accra: Ghana Statistical Service.

Gillion, R. (1985). Paternalism and Medical Ethics. British Medical Journal, 290, 1971-1972. http://dx.doi.org/10.1136/bmj.290.6486.1971

Goodman, K. W. (2010). Ethics, Information Technology, and Public Health: New Challenges for the Clinician-Patient Relationship. Journal of Law, Medicine and Ethics, 38, 58-63. http://dx.doi.org/10.1111/j.1748-720X.2010.00466.x

Gostin, L. O. (Ed.) (2002). Public Health Law and Ethics: A Reader. Berkeley, CA: University of California Press and the Milbank Memorial Fund.

Goulet, D. (1996). A New Discipline: Development Ethics. Working Paper No. 231, Kellogg Institute, the Hellen Kellogg Institute for International Studies.

Hart, H. L. A. (1994). The Concept of Law (2nd ed.), with Bulloch, P., \& Raz, J. (Eds.), Posthumous Postscript. Oxford: Clarendon Press. (Also 3rd ed., 2012.). Stanford CSLI 2016. http://www.plato.stanford.edu/entries/rights

Hedahl, M. (2013). The Significance of a Duty's Direction: Claiming Priority Rather than Prioritizing Claims. Journal of Ethics and Social Philosophy, 7, 1-28.

Heller, J. (1972). Syphilis Victims in US Study Went Untreated for 40 Years, Syphilis Victims Got No Therapy. New York Times, Associated Press.

Helsinki Declaration (1964). http://www.wma.sciencemuseum.org

Helsinki Declaration (1967). Helsinki.

Hohfeld, W. (1919). Fundamental Legal Conceptions (Cook, W. (Ed.)). New Haven, CT: Yale University Press.

Holmes, S., \& Sunstein, S. (1999). The Costs of Rights. New York: WW Norton.

Human Development Report (1990). UNDP. http://hdr.undp.org/en/reports/global/hdr1990

Human Development Report (2015). http://hdr.undp.org/en/2015-report

Johnson, R. (2014). Kant's Moral Philosophy. In E. N. Zalta (Ed.), The Stanford Encyclopaedia of Philosophy. http://plato.stanford.edu/entries/kant-moral/

Kamm, F. (1992). Non-Consequentialism, the Person as an End-in-Itself, and the Significance of Status. Philosophy and Public Affairs, 21, 354-389.

Louden, R. (1983). Rights Infatuation and the Impoverishment of Moral Theory. Journal of Value Inquiry, 17, 87-102. http://dx.doi.org/10.1007/BF00158554

Martin, B. (2016). http://bmartinmd.com/elixir-sulfanilamide-deaths/ 
Murove, M. F. (2009). African Bioethics: An Exploratory Discourse. In: M. F. Murove (Ed.), African Ethics: An Anthology of Comparative and Applied Ethics (pp. 157-177). Scottsville: University of KwaZulu-Natal Press.

Myrdal, G. (1969). Objectivity in Social Research (pp. 3-5). New York: Pantheon Books.

Norman, I. D. (2014). Access, Knowledge and Application of Public Health Law: A Case Study of Awareness of Lawyers, Medical Doctors and Nurses of Ghana's Legal Framework on Public Health. Advances in Applied Sociology, 4, 141-148.

http://dx.doi.org/10.4236/aasoci.2014.46018

Norman, I. D. (2015). Blind Trust in the Care-Giver: Is Paternalism Essential to the HealthSeeking Behavior of Patients in Sub-Saharan Africa? Advances in Applied Sociology, 5, 94-104. http://dx.doi.org/10.4236/aasoci.2015.52008

Norman, I. D. (2016a). Desperately Seeking the Tools of Ethics for Traditional Medicine Practice. Advances in Applied Sociology, 6, 255-260. http://dx.doi.org/10.4236/aasoci.2016.67021

Norman, I. D. (2016b). The Tools for Appraising Ethics for the Practice of African Traditional Medicine. Acta Bioethica.

Norman, I. D., \& Aviisah, M. A. (2015). Does Corruption in Ghana Manifest Post Traumatic Stress Disorder? Donnish Journal of Neuroscience and Behavioral Health, 1, 012-020. http://www.donnishjournals.org/djnbh

Nuremberg Code (1947). Nuremberg, Germany. www.wma.sciencemuseum.org

Onunwa, U. R. (2008). Contemporary Themes in African Religion and Culture. Pittsburgh, PA: Red Lead Press.

Osei-Hwedie, K. (1997). Southern African Regional Approaches to Indigenising Social Work Education and Practice: The Case of Botswana. In D, De Kock, T. Hall, W. Hayden, et al. (Eds.), Indigenisation in Social and Community Work Education (pp. 41-58). Pretoria: Human Sciences Research Council.

Rachels, J. (2003). Elements of Moral Philosophy (4th ed.). New York: McGraw Hill Company Inc.

Ross, E. (2010). Inaugural Lecture: African Spirituality, Ethics and Traditional Healing-Implications for Indigenous South African Social Work Education and Practice. South African Journal of Bioethics and Law, 3, 48-51.

Seers, D. (1969). The Meaning of Development. IDS Communication No. 44, UK: Institute of Development Studies.

Sen, A. (1979). Equality of What? The Tanner Lecture on Human Values. Stanford: Stanford University.

Sen, A. (1982). Inequality Re-Examined. Oxford: Clarendon Press.

Sen, A. (1985). Commodities and Capabilities. Amsterdam: North-Holland.

Sen, A. (1995). Rationality and Social Choice. American Economic Review, 85, 1-24.

Sivalingam, N. (2011). Medical Paternalism and Patient Autonomy. The Dualism Doctors Contend with.. Medical Journal of Malaysia, 66, 421-422.

Smithells, R. W. (1962). Thalidomide and Malformations in Liverpool. Lancet, 1, 1270-1273. http://dx.doi.org/10.1016/S0140-6736(62)92367-X

Smithells, R. W. (1973). Defects and Disabilities of Thalidomide Children. British Medical Journal, 1, 269-272. http://dx.doi.org/10.1136/bmj.1.5848.269

Stanford CSLI (2016). The Stanford Centre for the Study of Language and Information. 
Udokang, E. J. (2014). Traditional Ethics and Social Order: A Study in African Philosophy. Cross-Cultural Communications, 10, 266-270.

World Medical Association (WMA) (1964). http://www.wma.sciencemuseum.org

Submit or recommend next manuscript to SCIRP and we will provide best service for you:

Accepting pre-submission inquiries through Email, Facebook, LinkedIn, Twitter, etc. A wide selection of journals (inclusive of 9 subjects, more than 200 journals)

Providing 24-hour high-quality service

User-friendly online submission system

Fair and swift peer-review system

Efficient typesetting and proofreading procedure

Display of the result of downloads and visits, as well as the number of cited articles

Maximum dissemination of your research work

Submit your manuscript at: http://papersubmission.scirp.org/

Or contact aasoci@scirp.org 